\title{
FACILIDADES ESENCIALES Y ABUSO DE POSICIÓN DOMINANTE*
}

\section{ALFREDo UgarTe SoTO**}

RESUMEN: El presente trabajo describe la situación actual del desarrollo y avance tanto doctrinal como jurisprudencial del derecho de la libre competencia, respecto de la institución de las facilidades esenciales y el abuso de posición dominante que realizan determinadas empresas en el mercado nacional, limitando o impidiendo el ingreso de nuevos competidores. Así, se busca explicar cuáles son las características, condiciones y requisitos necesarios para determinar cuándo dentro de una estructura de libre competencia estamos frente a lo que la doctrina conoce como "essential facilities". Las principales interrogantes que se tratan de responder dicen relación en primer lugar con determinar qué es lo que la doctrina y jurisprudencia han entendido por facilidades esenciales, cuál es el verdadero alcance y sentido de este concepto, y como no tanto el derecho chileno como el comparado han abordado la procedencia y aplicación de esta teoría. Se enfocará posteriormente en analizar los criterios materiales y subjetivos que configuran la posición dominante en relación a una instalación esencial, especialmente respecto al mercado relevante en la cual está inserta y cómo la naturaleza jurídica y las características distintivas de cada uno de estos influyen directamente sobre la libre competencia.

PALABRAS CLAVE: Libre competencia - facilidades esenciales - posición dominante - mercado relevante

\section{ESSENTIAL FACILITIES AND THE ABUSE OF A DOMINANT POSITION}

ABSTRACT: The present paperwork describes the current situation of the doctrinal and jurisprudential development and advancement of the Free Competition Law, on respect of the essential facilities institution

Fecha de recepción: 4 de enero de 2013.

Fecha de aceptación: 29 de agosto de 2013.

** Abogado. Licenciado en Ciencias Jurídicas y Sociales, Pontificia Universidad Católica de Valparaíso. El presente trabajo ha sido realizado en el marco del programa de Magíster en Investigación Jurídica, Universidad de los Andes. Correo electrónico: augarte@uyhabogados.cl 
and the abuse of the dominant position carried out by some corporations in the national market, limiting and preventing the entrance of new competitors. Thus, it seeks to explain which are the characteristics, conditions and requirements needed to determinate when, in a free competition structure, we are in front of what the doctrine defined as "essential facilities".

The principal questions that this paperwork seeks to answer are related, in first term, with determining what the doctrine and the jurisprudence have understood by essential facilities, which is the real scope and sense of this concept, and how Chilean and international law have addressed the provenance and application of this theory. Subsequently it will focus on analyzing the material and subjective criteria that configure the dominant position in relation of an essential facility, especially in respect of the dominant market in which the company operates, and how the legal nature and the distinctive features of each one of these markets, directly influence on the free competition.

KEY WORDS: Free competition - essential facilities - dominant position - relevant market

\section{I) INTRODUCCIÓN}

La libertad de empresa es un derecho que poseen todos los ciudadanos y que les permite acceder a un mercado determinado como competidores, mantenerse dentro de él a través de la eficiencia económica y cesar en su ejercicio en el momento que lo deseen. Entendemos por libertad económica un concepto asociado y propio de la economía de mercado. Esto supone que la actividad económica se determina por la producción o el consumo de aquello que el precio haga más atractivo ${ }^{1}$; así, del ejercicio y consolidación de la libertad económica (género) se deriva la libertad de empresa (especie) en virtud de la cual todo ciudadano goza del derecho a emprender y a desarrollar una actividad económica en condiciones de igualdad, sin restricciones discriminatorias en un mercado libre, sin barreras de ingreso que impidan su derecho a emprender. Tal derecho está consagrado y protegido en nuestra Constitución Política (artículo 19 no 21), no pudiendo en caso alguno ser afectado en su esencia ni impedido su libre ejercicio mediante la imposición de condiciones o exigencias ajenas al orden jurídico establecido.

Quien primero desarrolló estos conceptos fue Adam Smith, en su libro Investigación sobre la naturaleza y causa de las riquezas de las naciones (Capítulo VII del Precio Natural y del Precio de Mercado de los Bienes), primera edición ańo 1776, disponible en versión en español décimo quinta reimpresión, ańo 2006, Fondo de Cultura Económica, México, D.F. 
La doctrina de las Facilidades esenciales limita la libertad de empresa y restringe la posibilidad de un agente económico de ejercer legítimamente una posición monopolística. La excepción a una de las reglas fundamentales de las economías de libre mercado y que constituye la obligación de contratar con un competidor debe entenderse de forma restrictiva, y teniendo en consideración su equilibrio y aplicación conjunta con la protección de la libre competencia, sin afectar la libertad de empresa ni tampoco a esta última.

Cabe destacar que la competencia es un fenómeno jurídico que constituye el motor organizativo de todo el sistema económico, al tiempo que opera como límite regulador de las situaciones que pudieran alterar el equilibrio necesario para su eficiente desarrollo. Se comporta como principio rector de toda la economía de mercado, representa un elemento consustancial al modelo de organización económica de nuestra sociedad y constituye, en el plano de las libertades individuales, la primera y más importante forma en que se manifiesta el ejercicio de la libertad de empresa ${ }^{2}$.

En el derecho de la libre competencia, la regulación del uso de Facilidades esenciales $-\mathrm{o}$ essential facilities ${ }^{3}{ }^{3} \mathrm{y}$ del abuso de posición dominante tiene por objeto favorecer la existencia de una estructura de mercado eficiente, protegiendo la competencia frente a todo ataque contrario al interés público y regulando el comercio mediante la prohibición de restricciones ilegales. El objetivo de tal regulación, por lo mismo, es evitar que el controlador (dueńo, arrendatario, concesionario, etc.) de un activo de carácter "imprescindible" abuse de su posición, obligándolo en función de la libre competencia a facilitar sus estructuras a los competidores con el propósito de que en un mercado relevante determinado, ya sea de bienes o servicios, pueda existir una armónica y justa competencia económica entre los distintos actores u operadores. Se busca impedir y sancionar, por ende, las conductas monopólicas abusivas que algunos agentes económicos puedan ejercer ilícitamente y que perjudiquen al consumidor, atentando contra la libre competencia.

El presente estudio busca explicar precisamente cuándo una estructura posee las características y condiciones necesarias para ser considerada esencial en una dinámica de libre competencia. Se intentará establecer,

2 Bolivar Gacitúa, Natalia (2010), Las concentraciones de empresas, regulación y criterios de decisión de los órganos de la Unión Europea, Memoria para optar al grado académico de Máster en Derecho Privado Patrimonial. Salamanca: Universidad de Salamanca, Facultad de Derecho, Departamento de Derecho Privado, p. 5.

3 Como señala el artículo 2 de la Sherman Antitrust Act, norma fundamental del derecho de competencia norteamericano, en un comienzo se consideraban recursos esenciales las infraestructuras físicas de transporte que presentaban características de monopolio natural, pero luego dicho concepto ha ido evolucionando a otras situaciones y casos como lo son el uso de redes de transporte de información, uso de intangibles como los derechos protegidos por la propiedad intelectual, etc. 
entonces, cómo y qué requisitos de una instalación confieren dicho carácter, cuáles son las condiciones en que se configura un atentado o perjuicio que afecte a la libre competencia y, en fin, su relación con la posición y abuso del poder de mercado que tiene una empresa en un mercado relevante determinado. Para ello se analizará en este trabajo (1) qué entendemos por "Facilidades esenciales"; (2) cómo se adquiere la posición de dominio por medio de una instalación esencial; (3) la existencia y relación entre instalación esencial y posición dominante en un mercado relevante; (4) cómo afecta esta relación en la libre competencia.

\section{1) FACILIDADES ESENCIALES. CONCEPTO Y ELEMENTOS DISTINTIVOS}

La doctrina de las facilidades o instalaciones esenciales forma parte de la jurisprudencia antimonopolio de los Estados Unidos de Norteamérica, surgida en el año 1912 con motivo del conocimiento por parte del Tribunal Supremo del caso "United States v/s Terminal Railroad Association of St. Louis". A raíz de este conflicto, que incidía concretamente en el mercado del transporte ferroviario de ese país, se planteó por primera vez el efecto perjudicial para la libre competencia que genera o puede generar el control monopolista ejercido por una empresa controladora de una determinada infraestructura o facilidad, esencialmente necesaria para participar eficientemente en un mercado determinado. La solución en este caso consistió en obligar a la empresa controladora de la facilidad (líneas ferroviarias, puentes, puestos de control de entrada y salida de la ciudad, etc.) a compartir sus estructuras esenciales con los demás competidores, previo pago de una tarifa ajustada al uso ordinario de dichas estructuras esenciales y que no desincentivara, en razón de su cuantía precisamente, la posibilidad real de acceder a ellas y de competir con la empresa controladora en un plano de igualdad.

Con posterioridad se fueron originando diversos fallos en ese sentido, siendo importante de destacar el caso "Hecht v/s Pro-football Inc." en el cual se estableció, en lo que aquí concierne, que cuando una instalación no puede ser duplicada por los competidores nace la obligación para quien está en posesión de ella de compartirla en términos justos y razo-

4 Disponible en: http://caselaw.lp.findlaw.com/scripts/getcase. pl?court=us\&vol=224\&invol=383 y en http://www.met.psu.edu/people/ank1/researchpapers/reiffen\%20and\%20kleit.jle.pdf . Consultado el 22 de junio de 2011.

5 Hecht v. Pro-Football, INC. (570 F.2d 982 (D.C. Cir. 1977). Disponible en: http:// federal-circuits.vlex.com/vid/herht-kagan-venturers-federal-football-38433465, Norman F. Неснт, Harry Kagan and Marc A. Miller, joint venturers, Appellants, Washington Federals, Inc., a corporation, et al. v. Pro-Football, INC., a corporation, et al. No. 75-1819. United States Court of Appeals, District of Columbia Circuit. Argued December 20, 1976. Decided December 20, 1977. 
nables, considerándose ilegal restringir el comercio por la vía de negar el acceso a facilidades escasas ${ }^{6}$. De esta jurisprudencia surge precisamente la denominada "Doctrina de las Facilidades esenciales"7, de la que nos ocuparemos en esta investigación.

\section{1) CONCEPTO Y CONTENIDO DE LAS ESSENTIAL FACILITIES}

Las Facilidades esenciales constituyen activos de carácter corporal o incorporal (estructuras físicas, redes de transmisión, oleoductos, derechos de propiedad industrial, concesiones, etc.) que otorgan un beneficio económico a quien los detenta, por sobre sus competidores, y cuya existencia genera por lo mismo un desequilibrio entre ellos. Este efecto, producido naturalmente por el control de dichos activos, se justifica por la importancia o el carácter esencial que detentan estos últimos y el poder que tienen para colocar en una posición superior o dominante a quien los controla ${ }^{8}$.

6 Pitofsky, Robert (2002) The Essential Facilities Doctrine under United States. Disponible en http://www.ftc.gov/os/comments/intelpropertycomments/pitofskyrobert.pdf. Consultado el 14 de noviembre de 2011.

$7 \quad$ Al referirse a este tema, Astesiano señala: "Finalmente arribamos al primer caso en el cual el término Essential Facility es utilizado expresamente, por un tribunal en 1977, Hecht v. Pro-Football, Inc.30 En este caso, el actor que se encontraba negociando una licencia de la liga nacional de football americano y decide accionar contra la cláusula del contrato de locación del estadio por la cual se prohibía la locación del mismo a cualquier otro equipo de football americano que no fuera sus actuales usuarios (Redskins), lo cual lo obligaba a construir un nuevo estadio para poder obtener la licencia. La acción fue resuelta en primera instancia por un jurado que calificó la cláusula en cuestión como lícita. En apelación una de las cuestiones planteadas fue si el fallo de primera instancia era equivocado por no aplicar la doctrina de las facilidades esenciales, pues para los apelantes el estadio configuraba una facilidad esencial. La corte de apelación resolvió la cuestión reconociendo por primera vez la existencia de la doctrina, sosteniendo: "La doctrina de las facilidades esenciales, también llamada bottleneck principle, establece que cuando una instalación no puede prácticamente ser duplicada por quienes podrían ser competidores, quienes están en posesión de las instalaciones deben permitir a sus competidores compartirlas en términos justos y razonables. Es ilegal restringir el comercio negando el acceso a facilidades escasas. Este principio deriva del caso Terminal Railroad y fue recientemente confirmado en Otter Tail; este principio ha sido reiteradamente invocado por las cortes inferiores". (Astesiano, Gastón, "La Doctrina de las facilidades esenciales en los Estados Unidos de Norteamérica y su recepción en el Derecho argentino. Una primera aproximación”, p. 9 (LLM Universidad de Columbia, Seminario de Investigación Universidad Torcuato Di Tella, Buenos Aires, Argentina, Año 2002.). (Disponible en http://cdi.mecon.gov.ar/biblio/docelec/mu1007.pdf Consultado el 14 de noviembre de 2011).

8 La Organización Mundial de Comercio, refiriéndose al concepto de proveedor importante en materia de servicios de telecomunicaciones, entrega una definición distinta al señalar que "es aquél servicio o infraestructura que es suministrado por un solo proveedor o por un número limitado de proveedores, y cuya sustitución con miras al suministro de un servicio no sea factible en lo económico o en lo técnico" (Organización Mundial del Comercio (2004) México, medidas que afectan a los servicios de telecomunicaciones, Informe del grupo especial, Suiza. Disponible en http://www.regimenjuridicodelcomercioexterior.com/pdf/MexicoMedidas.pdf. 
En otros términos, el concepto de Facilidades esenciales, o essential facilities, consiste en identificar aquellas situaciones en que un monopolista, controlador de un bien indispensable para la realización de una actividad económica en un mercado relevante, impide a otros competidores el uso del bien esencial o le impone condiciones gravosas y discriminatorias para su utilización, sin que existan razones jurídicas, técnicas o comerciales para hacerlo. Como consecuencia de ello se restringe la competencia entre los distintos competidores, ya sea por imposibilidad de ingresar al mercado o por lo inviable que resulta el ingreso a una actividad comercial con fuertes barreras de entrada, generadas precisamente por la circunstancia de no tener acceso a tales Facilidades esenciales. En virtud de lo anterior, y con el objeto de regular el mercado por decisiones de la autoridad competente, se obliga al monopolista a contratar con el competidor en condiciones de equilibrio razonables y no discriminatorias?.

\section{2) LAS FACILIDADES ESENCIALES EN EL DERECHO CHILENO Y COMPARADO}

En el derecho comparado, la doctrina de las Facilidades esenciales se ha ido configurando sobre la base de dos grandes sistemas, que provienen de tradiciones jurídicas distintas.

Por una parte, en efecto, el sistema europeo se basa en las normas contenidas en el Tratado Constitutivo de la Comunidad Europea -o "Tratado de Roma" - y concretamente en su artículo 82 (ex 86), sobre abuso de posición dominante. Tratándose de las Facilidades esenciales, la Comisión Europea de Competencia las ha definido teniendo como referencia el mercado de las telecomunicaciones, señalando al respecto que "Se utiliza la expresión 'instalación esencial' para describir aquellas instalaciones o infraestructuras que son básicas para llegar a los consumidores y permitir a los competidores llevar a cabo sus actividades y no pueden ser sustituidas por ningún medio razonable" 10 .

En el sistema norteamericano, en cambio, el concepto de Facilidades esenciales se genera a partir de la interpretación y aplicación que los tribunales de Estados Unidos han dado a las normas contenidas en las secciones 1 y 2 de la Sherman Antitrust Act, y del desarrollo jurisprudencial posterior ${ }^{11}$.

9 Villar Rojas, Francisco José (2005), Las Instalaciones esenciales para la competencia. Granada: Comares, p. 15.

10 Comisión de Competencia de la Unión Europea (1998), Comunicación sobre la aplicación de las normas de competencia a los acuerdos de acceso en el sector de las telecomunicaciones. DO C n ${ }^{\circ} \mathrm{C} 265$ de 22/08/1998.

$11{ }^{11}$ Calvo Caravaca, Alfonso; Rodríguez Rodrigo, Juliana (2012), "La Doctrina de las Infraestructuras Esenciales en Derecho Antitrust Europeo", en "Revista de Derecho de la Competencia y la Distribución”, Monografía N 6, Numeral 13, Madrid: Wolters Kluver, p. 49. 
En Chile, ha tenido reconocimiento jurisprudencial la doctrina de las Facilidades esenciales, incluso con anterioridad al Tribunal de Defensa de la Libre Competencia (TDLC), creado en $2003^{12}$. De hecho, se puede observar su aplicación práctica en algunos casos resueltos por las antiguas comisiones, especialmente la Comisión Resolutiva y la Comisión Preventiva Central. Recientemente y luego de su creación, sin embargo, el TDLC sobre esta materia ha fallado de manera contradictoria los conflictos de competencia sometidos a su conocimiento, según veremos durante el desarrollo del presente estudio.

\section{2) REQUiSITOS Y ELEMENTOS DE PROCEDENCIA Y APLICACIÓN DE LA TEORÍA DE LAS FACILIDADES ESENCIALES}

El precedente más importante de la doctrina de las facilidades esenciales, a través del cual se establecieron de modo jurisprudencial los requisitos de existencia de la misma, fue el caso " $M C I$ Communications $v / s$ AT\&T Co." 13 , que trata de la negativa unilateral de un monopolista (AT\&T) en cuanto a permitir que su competidor tuviese acceso a su red local en el mercado de larga distancia (MCI). La Corte federal de apelaciones del séptimo distrito de E.E.U.U. encontró a AT\&T responsable por violación a la Sherman Act, fundando su decisión en la doctrina de las Facilidades esenciales y estableciendo los cuatro elementos necesarios para que exista responsabilidad derivada de su aplicación al caso concreto, esto es: (i) titularidad o control de la facilidad esencial por un monopolista, (ii) imposibilidad práctica para un competidor de duplicar la facilidad esencial, (iii) la denegación de acceso al competidor de la facilidad y, por último, (iv) factibilidad de proveer acceso a la facilidad.

En lo que sigue nos detendremos entonces en el análisis de cada uno de estos requisitos, a los que agregaremos todavía otros dos que la doctrina ha mencionado especialmente ${ }^{14}$.

12 En este sentido Álvaro Araya Ibáńez, en su trabajo sobre la doctrina de las facilidades esenciales en los fallos del TDLC, señala: "la doctrina de las facilidades esenciales no tiene en Chile un desarrollo legislativo explícito. Pese a ello, es unánime en nuestra jurisprudencia que las conductas abusivas del controlador de una facilidad esencial pueden enmarcarse sin fuerza dentro de la normativa general de infracciones a la libre competencia establecidas por el Decreto Ley 211 (DL 211), específicamente la figura de negativa a contratar o la de abuso de posición dominante", la "Doctrina de las Facilidades Esenciales en los fallos del Tribunal de Defensa de la Libre Competencia”, Novoa \& Araya Abogados Limitada, Serie notas y artículos de interés Número 1, septiembre 2011, p. 3, disponible en http://www.nyaabogados.cl/docs/NotasyArticulosNA N1 Facilidades\%20Esenciales.pdf, consultado el 17 de diciembre de 2012.

13 Disponible en http://www.arinoyvillar.com/libros/nuevoserv/instalacionesesenc.pdf, consultado el 14 de abril de 2012 .

14 Rencoret Gutiérrez, Pēro (2010), La Doctrina de las facilidades esenciales ante el Tribunal de Defensa de la Libre Competencia (Memoria para adquirir el grado académico de 


\section{1) CONTROL DE UNA INSTALACIÓN POR UN MONOPOLISTA}

El titular de la facilidad esencial es aquella persona natural o jurídica que detenta el control de la misma por diversos títulos o calidades jurídicas, sin ser necesariamente su propietario. Se habla por lo mismo de controlador o de titular de la facilidad esencial por cuanto dicho control puede derivar del dominio que se tiene sobre ella o, también, porque se es poseedor o tenedor de la misma en calidad de usufructuario (el caso típico de las concesiones), arrendatario, licenciatario, etc. Al titular de la situación privilegiada descrita supra le conviene restringir el acceso a las estructuras esenciales, pues en virtud de ella monopoliza el mercado como consecuencia de la creación, mantenimiento o reforzamiento de una posición de dominio, en detrimento de sus competidores. Por ello, la aplicación de la doctrina de essential facilities solo tiene sentido si el monopolista tiene poder de mercado ${ }^{15}$, al punto que sin este no es posible que haya posición dominante ni, por ende, abuso de facilidades esenciales.

A su vez, y conjuntamente con lo anterior, se puede señalar que la titularidad de la estructura esencial -pública o privada - es indiferente, ya que lo relevante para estos efectos es la negativa injustificada del controlador de otorgar la facilidad para permitir su uso a los demás competidores, amén del carácter de esencial de la instalación.

La instalación esencial debe estar controlada entonces por el monopolista, es decir, por una empresa que tenga una posición dominante en un mercado relevante. El poder monopólico que el control de la instalación otorga, consiste en ejercitar de forma exclusiva la oferta o la demanda de un producto, lo cual se traduce en determinar a propia voluntad el precio, la cantidad o calidad, las condiciones contractuales y otras variables de mercado referidas a ese producto determinado ${ }^{16}$.

Este control puede derivar, a su vez, de varias fuentes, de manera que el monopolista puede haber obtenido su poder por vía legal (monopolios de privilegio), por vía natural (monopolios naturales), por la eficiencia económica en el desarrollo de sus actividades comerciales, etc. Cualquiera

Licenciado en Ciencias Jurídicas y Sociales). Santiago: Universidad de Chile, Facultad de Derecho, Departamento de Derecho Económico, p. 45.

15 Poder de mercado es definido como la capacidad de una única empresa o de varias empresas competidoras para elevar los precios en beneficio propio por encima de los niveles de precios de competencia y restringir ofertas por debajo de los niveles de competencia durante un periodo sostenido de tiempo. Este concepto es compartido por la doctrina y la jurisprudencia, en especial por el Departamento de Justicia de EE.UU. (DOJ) y, en particular, por la OCDE en Policy Brief de la OCDE Substantial Market Power and Competition, disponible en http://www.oecd.org/regreform/liberalisationandcompetitioninterventioninregulatedsectors/41257462.pdf.

16 Valdés Prieto, Domingo (2006), Libre Competencia y Monopolio, Santiago: Editorial Jurídica, p. 44. 
que sea la fuente de dicho poder monopólico, sin embargo, puede derivar en una conducta prohibida y sancionada por la ley cuando su ejercicio se torna abusivo, según se verá más adelante.

\section{2) CARÁCTER IMPRESCINDIBLE Y NECESARIO DE LA INSTALACIÓN PARA PODER COMPETIR EN EL MERCADO DE LA EMPRESA QUE LO POSEE O CONTROLA}

El carácter esencial exigido para la aplicación de la teoría en comento comprende dos requisitos copulativos, esto es: (a) que la instalación sea indispensable para que exista competencia, y (b) que esta no pueda ser duplicada o replicada. Esto quiere decir que al no existir bienes sustitutos y complementarios de la instalación, esta resulta esencial para que exista dicha competencia.

En términos económicos, debe tratarse entonces de un activo empresarial indispensable para la realización de determinadas actividades económicas, que no sea fácilmente replicable ${ }^{17}$. Asimismo, que una facilidad sea o no replicable dependerá del retorno económico que espera obtener el competidor con la duplicidad de la facilidad, de manera que si dicho retorno no es altamente rentable ni beneficia al competidor en términos tales que lo coloque en un plano de igualdad con el monopolista, la facilidad se convierte en imposible de replicar.

A este efecto, en los considerandos 139 y siguientes de la sentencia dictada recientemente por el Tribunal de Justicia de las Comunidades Europeas, en que se condenó a la empresa Microsoft por conductas reñidas con la libre competencia, se reafirma la idea de las dificultades para replicar un insumo estratégico que, además, tiene el carácter de "insustituible" y respecto del cual existe una alta demanda, factores que impiden su duplicación, al mismo tiempo que incentivan a los competidores a intentar crear sustitutos tanto o más rentables que la facilidad existente. En este caso, la sentencia condenó a Microsoft por negarse a proporcionar a sus competidores interoperabilidad entre sus productos y por las ventas atadas impuestas a los consumidores ${ }^{18}$.

Por otro lado, será técnica o legalmente inviable de replicar si para implementarla se requieren determinadas autorizaciones legales, imposibles o muy difíciles de obtener, o bien, si existen impedimentos de tipo técnico como la creación de plataformas informáticas (caso de las tarjetas de crédito red Transbank), redes con demanda bilateral (Chile, 2005,

17 Calvo Caravaca, Alfonso; Rodríguez Rodrigo, Juliana (2012) Numeral 172, p. 258.

18 Sentencia del Tribunal General (Sala Segunda), Asunto T167/08, de 27 de junio de 2012. Disponible en: http://curia.europa.eu/juris/liste. jsf?language $=$ es \&jur=C, T,F\&num $=\mathrm{T}-167-08 \& \mathrm{td}=\mathrm{ALL}$. 
Sentencia del TLDC No 29/2005) ${ }^{19}$, o la construcción de estructuras físicas de gran tamaño.

Del mismo modo, una instalación es esencial cuando están involucradas estructuras básicas e imprescindibles que sirven para que los agentes económicos se desarrollen y compitan leal y libremente en una actividad concreta. En otras palabras, una instalación es esencial cuando "es el mercado el que depende de la instalación" 20 .

Este carácter de exclusividad es aplicable cuando se trata de bienes imprescindibles, ya sea física, geográfica o legalmente, lo que lleva precisamente a la necesidad de adecuar y regular su distribución en los mercados para hacerlos operativos. Asimismo, un insumo puede ser considerado como indispensable para competir cuando carece de sustitutos razonables, pues de lo contrario dejaría lógicamente de ser indispensable ${ }^{21}$.

Teniendo presente lo expuesto, vemos entonces que la doctrina de las Facilidades esenciales se sustenta en la premisa de que un recurso es esencial cuando la instalación es vital para el suministro de bienes o servicios en mercados relevantes o conexos. La mayoría de los autores sostiene, por lo mismo, que para aplicar la teoría de las Facilidades esenciales debe acreditarse la existencia de dos mercados distintos y verticalmente integrados, de modo que el controlador de la Facilidad esencial puede extender su poder de mercado, de un mercado "aguas arriba" a otro "aguas abajo". En este sentido, Humpe y Ritter ${ }^{22}$ afirman que deben existir dos mercados verticalmente relacionados, y que tanto el demandante como el monopolista deben tener presencia en ambos.

En síntesis, y a pesar de que no existe una regla única que permita establecer un parámetro exacto que sea infalible al momento de considerar un bien como esencial, el estándar de esencialidad debe ser necesariamente alto, partiendo de la base de que un monopolista siempre tendrá algo que sus competidores o potenciales competidores desean. Dicho en otros términos, si un competidor pudiera duplicar la facilidad a un costo razo-

19 Caso Tarjetas de crédito red Transbank/redes con demanda bilateral, Sentencia Tribunal de Defensa de la Libre Competencia N²9/2005, de fecha 12 de septiembre de 2005. La conducta ilícita, en este caso, es la de abuso de posición dominante. La sentencia se basó en tres elementos principales para justificar su decisión: primero, que en su carácter de monopolista respecto de los terminales electrónicos de autorización y captura de transacciones cobraba un precio abusivo; segundo, se discriminaba de forma arbitraria, también, en cuanto a los cobros entre establecimientos comerciales que eran parte de su red comercial y aquellos que no lo eran; y tercero, se cobraba el mismo valor respecto de las transacciones efectuadas con tarjeta de crédito y las realizadas con tarjetas de débito, teniendo en cuenta que los costos de operación respecto de una u otra varían sustancialmente.

Villar (2005) 18.

Rencoret GutiérRez (2010) 65

Humpe, Christophe, Ritter, Cyril (2005), Refusal to deal, Brussels, Global Competition Law Centre, julio, p. 32. Disponible en www.http:/ssrn.com/abstract=771907>. Consultado el 14 de abril de 2012. 
nable, el acceso del competidor a la facilidad del monopolista perdería el carácter de esencial ${ }^{23}$.

\section{3) INVIABILIDAD PRÁCTICA O ECONÓMICA DE REPLICAR LA REFERIDA INSTALACIÓN ESENCIAL}

Otro aspecto distintivo de la instalación esencial consiste en que la construcción o habilitación de una nueva instalación esencial no es técnica ni económicamente viable. Determinar, en consecuencia, cuándo la construcción o habilitación de una facilidad esencial se hace inviable es de suma importancia, por ser precisamente esta situación la que le da el carácter de esencial y le otorga el beneficio de hacerla tan apetecida por el monopolista y sus competidores. Así ocurre, por ejemplo, en el caso del mercado de la sal y el mercado portuario de la Primera Región, en los cuales existían barreras legales que impedían la utilización por parte de otras empresas no concesionarias del puerto en disputa, considerando que la concesión otorgada por la autoridad portuaria es de carácter exclusivo. En otros casos, en cambio, las barreras son de carácter técnico o económicas, y en otros, en fin, una mixtura de factores dependiendo de las circunstancias materiales del sector o mercado y de las regulaciones legales asociadas.

\section{3) DENEGACIÓN DE USO A LOS COMPETIDORES (INSTALACIÓN ESENCIAL Y REFUSAL TO DEAL)}

La denegación debe provenir del titular de una determinada infraestructura, con el fin de impedir a sus competidores el acceso a ella y con esto eliminar o debilitar a la competencia.

El monopolista no se encuentra sujeto, por cierto, a un deber general de cooperar con sus rivales; sin embargo, en ciertas circunstancias su negativa a pactar con ellos y proveerles el acceso a la facilidad esencial puede ser lesivo a la libre competencia. En otras palabras, la sola posición monopólica de la empresa controladora de la facilidad no la hace merecedora de ningún reproche legal, sino que es precisamente su negativa injustificada y/o abusiva la que la pone en situación reprochable y configura una situación de competencia desleal.

Sobre este punto debe hacerse una distinción respecto de la doctrina del Refusal to deal o negativa de trato, que si bien se asemeja al instituto que analizamos, presenta una connotación y alcance mucho más restrictivo. La doctrina de las Facilidades esenciales constituye en efecto un tipo especial de negativa injustificada de contratar, consistente en negarse sin

23 Tovar Mena, Teresa (2006) Derecho de la Competencia y Telecomunicaciones. Lima, p. 179. 
que medie ninguna justificación a proveer a otras empresas del acceso al bien esencial para competir en igualdad de condiciones. La negativa de trato consiste, en cambio en un acuerdo entre empresas competidoras mediante el cual se niegan a hacer negocios con otro competidor, excluyéndolo de esta forma del mercado. Por ende, la doctrina de las Facilidades esenciales es más amplia y persigue un objetivo distinto, como es el sancionar toda práctica anticompetitiva en un mercado determinado, generada con ocasión de la negativa injustificada de proporcionar acceso a la facilidad ${ }^{24}$.

Debe advertirse, con todo, que los conceptos recién mencionados presuponen la concurrencia de elementos y aspectos que se deben evaluar en cada caso concreto, lo que implica que muchas veces sea imposible o al menos difícil determinar ex ante cuándo se está frente a una facilidad esencial -que determine precisamente la obligación de dar acceso a la misma ${ }^{25}$ - y no frente a otra figura diversa.

\section{1) INEXISTENCIA DE UNA LEGÍTIMA RAZÓN DE NEGOCIOS PARA DENEGAR EL USO DE LA INSTALACIÓN. INSTALACIÓN ESENCIAL Y DERECHOS INHERENTES}

Desde el punto de vista del negocio no debe existir ninguna razón legítima que le permita al controlador de la facilidad denegar el acceso a la instalación esencial. La existencia de una negativa a pactar sobre la facilidad esencial es precisamente aquello que da lugar a la aplicación de la doctrina. Por lo mismo, si no se niega el acceso solicitado desaparece el conflicto, haciendo de la doctrina un discurso jurídico puramente teórico.

La negativa de asistir a un rival puede recaer además tanto sobre facilidades de carácter tangible (como puertos, terminales ferroviarios o redes de transmisión eléctrica) como facilidades intangibles (tales como servicios o derechos de propiedad intelectual) ${ }^{26}$. En este punto, en consecuencia, la teoría en comento se entrelaza con otra llamada de los derechos inherentes, que parte de la premisa de que el titular de una patente u otro derecho de propiedad industrial tiene ciertas atribuciones -concedidas legalmente- para excluir a terceros que pretendieren utilizar el objeto de esos derechos de propiedad industrial, imponiendo restricciones sobre el licenciatario de esos derechos ${ }^{27}$.

Cabe destacar que los privilegios de propiedad industrial e intelectual forman parte de otro tipo de monopolio, esto es, el monopolio de

\footnotetext{
Calvo Caravaca/Rodríguez Rodrigo (2012) Numeral 50, p. 92.

Tobar Mena (2006) 177.

Rencoret Gutiérrez (2010) 81 y 82.

Cabanellas de las Cuevas, Guillermo (2010), Contratos de Licencia y Transferencia de

Tecnología en el Derecho Económico, Buenos Aires: Editorial Heliasta, p. 166.
} 
privilegio, ya que sin constituir un monopolio natural, dichos ámbitos se encuentran regulados por parte de la autoridad para evitar que se afecte a la libre competencia. Es así que el Estado y sus organismos suelen otorgar monopolios de privilegio con la finalidad de generar incentivos para la promoción de ciertas actividades económicas, o bien para el desarrollo de ciertas regiones de un país (zonas francas) ${ }^{28}$. Por ejemplo, en los mercados regulados la normativa de las actividades económicas es efectuada por autoridades públicas sectoriales, de modo tal que en ellas queda un escaso o, a veces, un nulo ámbito de aplicación de los principios de la libre competencia. En materia de Facilidades esenciales existen casos en los cuales estas coexisten dentro de un mercado regulado o bien pueden existir en un mercado sin reglamentación específica y es, precisamente en este último caso, en los que la ley no limita el acceso en igualdad de condiciones a dicha facilidad, sino que por el contrario, es el propio monopolista quien lo limita ejerciendo de manera abusiva su poder monopólico.

A este respecto es importante destacar el caso Trinko ${ }^{29}$, resuelto por la Suprema Corte de los Estados Unidos de Norteamérica, el año 2004. La empresa Verizon, encargada de prestar servicios de telefonía local, era la única compañía que prestaba servicios en este mercado y constituía, por lo tanto, un monopolio. Cuando entró en vigor la Telecommunications Act, de 1996, Verizon fue obligada a permitir el acceso a su infraestructura a los competidores que quisieran entrar en el mercado, para evitar de esa forma que el control de la facilidad constituyera una barrera de entrada a ese mercado.

La empresa monopolista cumplió, muy a su pesar, con la obligación de permitir el acceso de los nuevos competidores al bucle local; pero no les ofreció la misma calidad y estándar de servicio que ella disfrutaba respecto de dicho acceso. De esta forma, el servicio prestado por Verizon era superior al que otorgaban a las demás compañías, lo que motivó precisamente la denuncia de sus competidores.

Pese a que la agencia estatal estadounidense de comunicaciones (la FCC) consideró que el antiguo monopolista había incumplido la Ley de 1996, imponiendo reparaciones (sanción por infracción a la normativa vigente), un cliente de una de las empresas afectadas, Curtis V. Trinko, ejerció una "Class Action", demandando que la conducta de Verizon constituía también una infracción del derecho antitrust, de la que acabó conociendo el Tribunal Supremo de Estados Unidos. Dicha demanda fue rechazada ya que la Suprema Corte estimó que no se daban los elementos para la aplicación de la doctrina de las instalaciones esenciales, introduciendo como elemento diferenciador respecto de otros casos la existencia

VAldés Prieto (2006) 466 y 467.

Verizon Communications Inc. $v / s$ Law offices of Curtis V. Trinko, LL8 (02-682) 540 V.S. 398 (2004) 305 F. 3d 89, reversed and remanded. Disponible en www.ftc.gov/ogc/ briefs/02-682.pdf. 
de una autoridad estatal reguladora, cuyo poder normativo y sancionatorio inhibía la aplicación de tal institución. El caso Trinko, por lo mismo, se ha utilizado como argumento por quienes estiman que los tribunales deberían negarse a intervenir en cualquier industria en la que existe por mandato legal un ente estatal regulador que intervenga y cuente con poderes o facultades de control y sanción, independientemente de si ha sido eficaz en la aplicación de la ley ${ }^{30}$.

\section{2) FACTIBILIDAD DE PROPORCIONAR LA INSTALACIÓN ESENCIAL}

Otro elemento importante de considerar, para que estemos ante una instalación esencial, es que el titular de dicha infraestructura tenga la posibilidad real y efectiva de proporcionar el acceso a ella a quienes la solicitan. La factibilidad de beneficiar a otros usuarios y de que exista competencia es lo que motiva el acceso abierto.

En lo que respecta a los bienes básicos, la posición de que goza el dueño de la instalación esencial es dominante cuando impide que los competidores presten servicios o elaboren productos en el mercado relevante de aquel bien esencial, ya que les niega el acceso a tal activo imprescindible o se los otorga en condiciones menos ventajosas ${ }^{31}$.

\section{4) SituaCiOnES DE HECHO QUE ELIMINAN O RESTRINGEN LA CALIDAD DE INSTALACIÓN ESENCIAL EN UNA SITUACIÓN DETERMINADA}

El concepto de facilidades esenciales es aplicable cuando el activo involucrado tiene características de monopolio natural, es decir, existe por un hecho de la naturaleza, economías de escala, economías de ámbito, o por un determinado estadio de desarrollo de la tecnología que provoca que la mejor forma de explotación de un mercado relevante, desde un punto de vista productivo, sea la de un monopolio. ${ }^{32}$

\footnotetext{
30 Albeck B., David, Defining “Essential Facilities” after Trinko, pág. 7. Disponible en www. davidalbeck.com/writings/trinko.htm.

31 El caso Requerimiento de la Fiscalía Nacional Económica contra Sociedad Punta de Lobos S.A., Rol C-No 13-2004, es representativo de la aplicación de la doctrina de las estructuras esenciales, dada la posición dominante respecto de los bienes básicos. Uno de los argumentos que motivó la demanda y el requerimiento de la Fiscalía Nacional Económica se basó en la connotación de instalación esencial que se le dio al Puerto Patache para el embarque de la sal, ya que no existían otras alternativas técnicas ni económicamente idóneas para que hubiera una alternativa a Patache. En este caso se aprecia cómo una empresa que ocupa una posición dominante, discriminaba a otra para favorecer sus propias actividades, negando el acceso a un competidor o concediéndoselo en condiciones menos favorables que aquellas de que disfrutan sus propios servicios. Sentencia No 47/2006 de 5 de diciembre del año 2006 TDLC. VAldés Prieto (2006) 397-401.
} 
Por lo mismo, para obligar a una empresa a compartir sus facilidades con sus competidores deben darse las condiciones de existencia señaladas supra y, en términos generales, su aplicación debe darse solo en aquellos casos en los que compartir alguna instalación de la empresa dominante resulte realmente imprescindible para garantizar la competencia en el mercado $^{33}$. Así por ejemplo, la negativa de compartir relacionada con derechos de propiedad industrial o intelectual, supone una limitación de la libertad contractual, ya que la autoridad competente ha debido intervenir en este ámbito, exigiendo la transferencia de tales derechos a los competidores para asegurar el desarrollo del mercado ${ }^{34}$.

A este respecto, para Calvo y Rodríguez 35 "la doctrina de las infraestructuras esenciales se aplica también a bienes incorporales, como la propiedad intelectual o ciertos servicios considerados una infraestructura esencial". La jurisprudencia estadounidense -agregan estos autores- establece asimismo tres ideas fundamentales en este sentido:

" $\left.1^{\circ}\right)$ La existencia de un derecho de propiedad intelectual no constituye una barrera infranqueable a la aplicación de la doctrina de las infraestructuras esenciales.

$2^{\circ}$ ) En determinadas circunstancias, la negativa del titular de una propiedad intelectual a licenciar su derecho puede perjudicar el bienestar del consumidor.

$3^{\circ}$ ) Aunque no esté cubierta por un derecho de propiedad intelectual, la prestación de ciertos servicios (convenio de prestación de servicios de facturación, servicios de oficina centralizados, servicios de referencias médicas) puede equipararse (asimilarse) en determinadas circunstancias, a una infraestructura esencial para determinadas empresas (que prestan servicios de telefonía celular o suministran productos o servicios para el cuidado de la salud en el hogar)".

\section{II) AdQUisición de pOSICIÓN DOMINANTE POR MEDIO DE UNA INSTALACIÓN ESENCIAL}

La existencia de una determinada instalación esencial y su uso y aplicación con carácter de exclusividad por una empresa determinada puede implicar que, en corto tiempo, esta adquiera una posición dominante que le da un estatus superior respecto de su competencia, hecho que necesa-

\footnotetext{
33 Bello Martín-Crespo, María Pilar; Hernández Rodríguez, Francisco y otros (2009), Derecho de la Libre Competencia Comunitario y Español, Madrid: Thomson Aranzadi, p.137.

34 Odrizola, Miguel; Irissarry, Belén (2008), Derecho español de la competencia, Barcelona: Bosch, p. 177.

35 Calvo/Rodríguez (2012), 243.
} 
riamente debe tenerse en consideración al analizar los elementos que configuran una posición dominante.

\section{1) CONCEPTO Y ELEMENTOS DE LA POSICIÓN DOMINANTE}

La posición de dominio no está prohibida en sí misma, ni implica ningún reproche para quien goza de ella. Sin embargo, coloca a quien(es) la detenta(n) en una situación de responsabilidad que obliga a ser especialmente cuidadoso con el respeto al sistema de libre competencia. Así, conductas que en una situación de competencia se considerarían neutrales o incluso positivas, pueden ser consideradas abusivas si son realizadas por empresas en posición de dominio.

La posición dominante se manifiesta en el poder económico que tiene cada empresa, que le permite ejercer sobre el mercado una influencia notable y predecible ${ }^{36}$. Para que la posición sea dominante, por ende, es necesario que la empresa respectiva posea el poder económico que le permita independizarse de las decisiones de sus competidores, manejando discrecionalmente su capacidad de modificar precios e imponer otras condiciones comerciales en beneficio propio ${ }^{37}$.

\section{1) CRITERIOS MATERIALES Y SUBJETIVOS QUE CONFIGURAN LA PO- SICIÓN DOMINANTE}

La posición de dominio se considera según dos criterios complementarios y convergentes: (a) un criterio estructural, que describirá una situación objetiva de mercado, y (b) un criterio subjetivo de comportamiento y resultados, centrado en la conducta y en los logros de la empresa en dicho mercado. La posición de poder económico, a su vez, se caracteriza por dos rasgos definitorios: (a) otorgar a quien la detenta la posibilidad de obstaculizar una competencia efectiva, y (b) adoptar una estrategia independiente en el mercado ${ }^{38}$.

Algunos factores que contribuyen también a la posición dominante son la existencia de barreras de entrada en el mercado de que se trate, la competencia real y potencial en ese mercado, la cuota de mercado de los intervinientes y la posibilidad de elección por parte de terceros, lo que dependerá de la sustituibilidad de la demanda entre otros factores.

La posición dominante, en fin, depende y deriva de diversos factores que actúan de manera autónoma o simultánea, dependiendo de las ca-

Pascual y Vicente (2001) 263.

Odrizola/Irissarry (2008) 139.

Pellisé, Jaume (2002) Mercado relevante, posición de dominio y otras cuestiones que plantean

los artículos 82 TCE y 6 LEDC, Madrid: Civitas Ediciones, p. 217. 
racterísticas del mercado de que se trate, lo que presupone, por ende, la determinación ex ante del mercado relevante en cada caso, en cuanto base de todo y cualquier análisis.

\section{2) NECESIDAD DE DEFINIR EL MERCADO RELEVANTE}

Sobre el concepto de mercado relevante volveremos más adelante, al tratar sobre los efectos de la instalación esencial en un mercado relevante. Por ahora, adelantemos que para establecer si una empresa tiene o no poder dominante de mercado y, en definitiva, determinar si su conducta podría volverse abusiva, es preciso definir el mercado relevante en el cual se desenvuelve dicha empresa y si existen indicios reales, dadas las circunstancias de cada situación, de que tal abuso se verificará realmente ${ }^{39}$.

Normalmente, cuando se valora si una determinada conducta es abusiva se comienza definiendo el mercado relevante y evaluando la posición de la empresa en dicho mercado ${ }^{40}$. Dicho de otra manera, el análisis de una conducta restrictiva de la competencia requiere previamente determinar cuál es el contexto competitivo al que se enfrenta la empresa objeto de investigación. La definición del mercado relevante es, por tanto, un instrumento que se utiliza para comprender el contexto en el que se desarrolla la rivalidad competitiva entre las empresas y, cuando menos, sirve para realizar una primera aproximación sobre el posible dominio de la empresa objeto de investigación, como se explicará más adelante ${ }^{41}$.

\section{3) CRITERIOS DE DEFINICIÓN DE LA POSICIÓN DOMINANTE}

La posición de dominio, según se la ha descrito supra, otorga a quien la detenta la posibilidad de obstaculizar una competencia efectiva y de adoptar además una estrategia independiente en el mercado ${ }^{42}$. En tal sentido, su configuración in abtracto debe determinarse con base en dos criterios complementarios y convergentes, uno de carácter estructural-que

39 Pellisé, Jaume (2002), La Explotación Abusiva de una Posición Dominante (Arts. 82 TCE y LEDC), Madrid: Civitas Ediciones, p. 211.

40 Pellisé (2002) 119, señala al efecto: "En la doctrina de las "Essential Facilities" la posición de dominio se define sobre una situación de dependencia económica, por la que una o unas empresas necesitan de un medio o recurso básico que otra controla para poder desarrollar sus actividades. Lo que define la posición de dominio de la empresa en cuestión es el control que esta ejerce sobre esos medios o recursos que otras necesitan. La posición de dominio se detentará frente a la empresa o empresas que necesiten esos medios o recursos básicos".

41 Jiménez Latorre, Fernando, Cañizares Pacheco, Enrique (2005), "Dificultades para la definición del mercado relevante", Informe preparado para el Segundo Seminario de Derecho y Economía de la Competencia, Madrid: Fundación Rafael del Pino.

Pellise, Jaume (2002) 217. 
describe una situación de mercado- y uno de comportamiento y resultados, centrado en el accionar, la conducta y los logros de la empresa.

Asimismo, algunos factores que contribuyen a la posición dominante son la existencia de barreras de entrada en el mercado de que se trate, la competencia real y potencial en ese mercado, la cuota de mercado de los intervinientes y la posibilidad de elección por parte de terceros, lo que dependerá de la sustituibilidad de la demanda, entre otros factores.

\section{2) FACTORES JURÍDICOS A CONSIDERAR PARA DETERMINAR UNA POSICIÓN DOMINANTE}

Una empresa tiene una posición dominante cuando dispone de un poder o fuerza económica que le permita individualmente definir de manera autónoma y eficaz las condiciones del mercado en relación con los precios, las cantidades, las prestaciones complementarias, etc., sin consideración a la acción de otros empresarios o consumidores del mismo bien o servicio. La situación anterior puede darse además en dos casos, esto es, cuando el sujeto es el único oferente de un determinado bien o servicio en un mercado específico o cuando la empresa dominante no está expuesta a competencia sustancial, aun cuando no sea el único oferente en el mercado.

En tal sentido, entonces, son varios los factores, tanto estructurales como de conducta, que unidos entre sí determinan que una empresa se encuentre en una posición de dominio respecto de sus competidores en dicho mercado. Un ejemplo de lo anterior son las barreras de entrada al mercado, su composición estructural, las características de la demanda, la naturaleza de los productos que se comercializan en él, la posibilidad real de que la empresa mantenga un comportamiento independiente de sus competidores y tenga la expectativa cierta de aumentar los precios en el sector, etc. ${ }^{43}$.

\section{3) Posición dominante COleCtiva}

Podría darse el caso que la posición de dominio no pertenezca solamente a una empresa, sino que la detenten dos o más empresas competidoras, las cuales coordinan sus políticas comerciales.

En muchas oportunidades, en efecto, nos enfrentamos a infraestructuras o redes de conexión de gran magnitud, cuyo costo deben asumir por lo mismo dos o más empresas que adquieren por esa vía una posición dominante colectiva. En tales casos, por ende, la posición de dominio se

43 Navarro, María del Carmen (2004), Las Conductas Conscientemente Paralelas, Gaceta Juridica de la Unión Europea y de la Competencia, N²32, pp. 49-63. 
alcanza cuando distintos agentes económicos pertenecientes a un mismo mercado, o mercado conexo, coordinan su comportamiento para lograr una posición de dominio.

La teoría de la posición dominante colectiva surgió, precisamente, a propósito del conocimiento de la concentración de las empresas Airtours y First Choice en el mercado de los viajes combinados por parte de la Comisión de Competencia Europea ${ }^{44}$, la cual elaboró dicha teoría sobre la base de cuatro supuestos que podrían dar lugar a la existencia de este fenómeno:

a) La transparencia del mercado de referencia, el cual le permita a las empresas coordinadas comprobar si sus competidores siguen o no su misma línea.

b) La ausencia de presiones competitivas externas.

c) La existencia de incentivos para las empresas que alineen sus políticas comerciales, incentivos que existirán en la medida que los beneficios económicos producto de la coordinación sean mayores que los obtenidos sin ella, es decir, actuando cada competidor por separado, y

d) La existencia de mecanismos de castigo para aquellas empresas que no adhieran a la coordinación.

\section{III) EFECTOS DE LA PRESENCIA DE UNA INSTALACIÓN ESENCIAL Y DE POSICIÓN DOMINANTE EN UN MERCADO RELEVANTE}

Con lo explicado hasta aquí pueden definirse ya los elementos esenciales y básicos necesarios para estar en presencia de una facilidad esencial. Sin embargo, para la aplicación de la doctrina de las instalaciones esenciales no basta solo con detentar una posición de dominio, pues esta, además, debe ejercerse en el contexto de un mercado relevante.

\section{1) CONCEPTO DE MERCADO RELEVANTE}

La noción de mercado relevante supone identificar el conjunto de productos (bienes o servicios) que compiten entre sí en la satisfacción de las necesidades de los consumidores, el conjunto de empresas que pueden ofrecer dichos productos en un plazo relativamente reducido de tiempo y el área geográfica en la cual las condiciones de competencia para el su-

44 Decisión de la Comisión de las Comunidades Europeas, de fecha 22 de septiembre de 2009, por la que se declara una concentración incompatible con el mercado común (Asunto Airtours/First Choice), disponible en http://eu.vlex.com/vid/declara-incompatible-choicepertinente-fines-23541422. 
ministro de dichos bienes o servicios son suficientemente homogéneas, diferentes en todo caso de las de otras áreas geográficas próximas. Concretamente, el concepto de mercado relevante se utiliza como marco de referencia para cuantificar las cuotas de mercado de los operadores económicos de ese mercado. En consecuencia, mientras más restrictiva sea la definición del mercado relevante, mayor será la cuota de la empresa y más fuerte la presunción de su posición de dominio.

El mercado relevante debe definirse entonces en relación a dos dimensiones diversas:

\section{1) MERCADO DE PRODUCTOS}

Es la relación que existe entre los productos y servicios que los consumidores consideran intercambiables y los productos que los sustituyen. Por ende, este mercado depende de la sustituibilidad de la demanda y de la sustituibilidad de la oferta ${ }^{45}$.

La sustituibilidad, a su turno, se identifica con la presión competitiva más inmediata que enfrenta una empresa y viene dada por la posibilidad de que, en respuesta a un incremento en los precios de su producto, sus clientes decidan redirigir el consumo de este hacia otros productos o servicios que consideran sustitutivos de aquel, ya sea por razones técnicas, de precios o, en definitiva, por su capacidad para satisfacer una determinada necesidad de forma equiparable a la del otro producto.

Este elemento, por ende, consiste en determinar en qué grado es posible sustituir unos productos por otros, tomando en consideración aquellos que se comercializan en un territorio determinado. Tal concepto se instrumentaliza mediante la formulación de una variación hipotética de la relación entre el precio y el producto ofertado en el área que se examina, de manera que es la combinación producto/área y el hipotético aumento de los precios lo que determina el grado de fidelidad de los clientes con los productos ofrecidos por una empresa en un territorio determinado. Es lo que se denomina test de precios o test del monopolista hipotético ${ }^{46}$.

45 En forma análoga, creemos que debe considerarse el mismo criterio usado por la Organización Mundial del Comercio (OMC) para distinguir un producto similar: "Un producto que sea idéntico, es decir, igual en todos los aspectos al producto de que se trate, o, cuando no exista ese producto, otro producto que, aunque no sea igual en todos los aspectos, tenga características muy parecidas a la del producto considerado" (Acuerdo AD, art. 2.6; Acuerdo SMC, art. 15)

46 El test parte de un bien, por ejemplo, $X$, y un área geográfica, $A$. A continuación, se supone que el suministro del bien $\mathrm{X}$ dentro del área geográfica A está controlado por un monopolista (el monopolista hipotético) que decide incrementar de forma permanente los precios entre un $5 \%$ y un $10 \%$, seguidamente se evalúa si dicho incremento de precios resulta rentable: (i) si resulta rentable, se puede decir que el monopolista no enfrenta en el mercado de referencia restricciones competitivas que le impidan incrementar los precios, es decir, no existen sustitutivos de demanda u oferta, y por tanto, el bien $\mathrm{X}$ y el área geográfica $\mathrm{A}$ 
En conclusión, existirá un abuso de posición dominante en la medida que se controle un mercado específico de tal forma que dicho control le permita al monopolista independizar sus decisiones comerciales del resto de sus competidores.

\section{2) MERCADO GEOGRÁFICO}

Se refiere a la delimitación geográfica del mercado relevante y equivale, por lo mismo, al área territorial en donde se encuentran las fuentes alternativas a las que el consumidor podría acudir si el precio de un producto determinado se incrementara ${ }^{47}$.

\section{2) CUOTA DE MERCADO ${ }^{48}$}

Una vez que se establece la posición de dominio y se han considerado las valoraciones de las distintas operaciones, las cuotas de mercado determinan la existencia de la posición dominante. El criterio para establecer las cuotas de mercado se basa en el control del mercado, considerando el tamaño y madurez de este, la innovación, las formas de contratación, etc. ${ }^{49}$. En conclusión, la posición de dominio no se relaciona tanto con el tamaño de una empresa, sino con la posición relativa de una empresa en un mercado determinado.

constituyen un mercado relevante; (ii) por otro lado, si no resulta rentable dicho aumento de precios, esto indicaría que sí existen en ese mercado restricciones competitivas que impedirían al monopolista hipotético incrementar los precios. Cfr. Jiménez Latorre/CañIzares Pacheco (2005) 6.

47 La comunicación del Consejo Europeo relativa a la definición del mercado de referencia define al mercado geográfico de referencia como: “... la zona en que las empresas afectadas desarrollan actividades de suministro de los productos y de prestación de los servicios de referencia, en la que las condiciones de competencia son suficientemente homogéneas y que pueden distinguirse de otras zonas geográficas próximas debido, en particular, a que las condiciones de competencia en ella prevalecientes son sensiblemente distintas a aquellas" (Comunicación de la Comisión Europea relativa a la definición del mercado de referencia, D.O.C.E. 372 de 09/12/1997).

48 Al efecto, es importante destacar el trabajo del profesor de Harvard Law School, Louis KApLow, en "Why (ever) define markets" publicado en Harvard Law Review, año 2010, páginas 437 a 517, donde plantea su posición respecto de la debilidad de la aplicación del método de cuotas de mercado como elemento relevante para determinar el poder de mercado; sostiene que es la propia Ley en varias legislaciones locales la que normalmente utiliza y parece usualmente adoptar el modelo de definición de mercado/paradigma de cuota de mercado. Así, según su parecer, resulta evidente que los requerimientos existentes imponen un límite a la innovación en los métodos por el cual el poder del mercado es establecido, por ello, señala que el modelo de definición de mercado "paradigma de cuota de mercado" adolecería de debilidades e inconsistencias que no permitirían la utilización real y efectiva de éste. de la competencia, Unión Europea y España, Barcelona: Bosch 9.2.2, numeral 2217, p.1567. 


\section{3) APLiCaCión de la TEORÍa de las FACILIDAdes ESENCIALES EN RELACIÓN CON LA INTEGRACIÓN HORIZONTAL Y VERTICAL}

Determinada la posición dominante, es fundamental identificar las operaciones que se concentran en un mercado relevante, es decir, los efectos horizontales, verticales y los conglomerados.

El efecto horizontal se refiere a la concentración del operador en el aumento de las cuotas de mercado, lo que puede hacer desaparecer a un competidor con capacidad financiera para competir. Las consecuencias derivadas de este tipo de operaciones pueden producir el aumento de las cuotas de mercado de los intervinientes en él o bien la complementariedad de la actividades desarrolladas por cada una de las empresas en mercados distintos, que puede consistir en una complementariedad geográfica o en una ampliación de la gama de productos o servicios ofrecidos por las empresas afectadas por la operación.

El efecto vertical, en cambio, se relaciona con la presencia de mercado de un mismo agente en los procesos ascendentes y descendentes de la producción (concepto de "aguas arriba" y "aguas abajo", ya explicado), produciendo por un lado barreras de entrada y, por otro, contribuyendo a la exclusión de reales o potenciales competidores ${ }^{50}$.

En síntesis, ya sea que se trate de una integración horizontal y/o vertical de empresas, es aquí en donde se aplica precisamente la doctrina de las Facilidades esenciales, ya que los casos de negativa de suministros o de accesos limitados de insumos impiden al competidor que participe en una determinada actividad económica.

\section{4) Mercados CONEXos}

Un mercado conexo es aquel en donde una empresa con posición dominante en un mercado relevante, aprovechándose de su posición de preeminencia, ejerce efectos en otros mercados relacionados, configurando así su actuar abusivo. En este entendido, las facilidades esenciales se relacionan con dos mercados diversos aunque relacionados entre sí, pues mientras en uno se encuentra presente la instalación esencial, en el otro se lleva a cabo la producción o distribución de un determinado producto o servicio.

Tanto en las legislaciones antitrust norteamericana y europea, se aplican los mismos criterios de aplicación de la teoría en comento. En el

\footnotetext{
50 Navarro Varona, Edurne y Baches, Sergio (2004), El nuevo sistema comunitario de control de concentraciones, Actualidad jurídica, crónica de legislación y jurisprudencia de competencia, Madrid: publicación trimestral del Estudio de Abogados Uria Menéndez, No 8, pp. 37-50.
} 
asunto Tetra Pack ${ }^{51}$, el Tribunal estableció que, dados los estrechos vínculos existentes entre el mercado en que Tetra Pack mantenía una posición dominante y aquel en el que no ejercía un dominio, y la cuota tan elevada que poseía en el mercado dominado, la empresa se hallaba en una situación que podía equivaler al mantenimiento de una posición dominante en los mercados en su conjunto.

En consecuencia, ambas posturas pretenden proteger la competencia de un mercado dependiente, pero diferenciado ${ }^{52}$, mediante la aplicación de la teoría de las facilidades esenciales.

Por lo tanto, el efecto producido en un mercado puede tener consecuencias directas en aquellos que se encuentran relacionados entre sí, sin que sea necesario que los beneficios o desventajas que se produzcan a través de su aplicación, pertenezcan al mismo mercado en el que opera el monopolista.

\section{5) POSICIÓN DOMINANTE EN LOS MERCADOS SECUNDARIOS}

Para establecer la posición dominante en un mercado secundario ${ }^{53}$ es necesario determinar qué productos son accesorios de los del mercado primario. ${ }^{54}$ Así, mientras mayor es la competencia en el mercado primario y más fuerte es la posición del proveedor en tal mercado, es más probable que el operador ocupe una posición dominante en el mercado secundario, dando lugar incluso a ventas atadas que perjudiquen directamente a los consumidores. Esta práctica atenta contra la libertad de competencia en el ámbito convencional, puesto que se obliga a quien desea adquirir un determinado bien a que lo haga en vinculación forzada con otro bien adicional que no desea ni está dispuesto a demandar económicamente, práctica tipificada en el artículo $3^{\circ}$ b) del DFL 211 y que no se agota por lo demás en compraventas, sino que alcanza cualquier convención querida y efectivamente solicitada al monopolista ${ }^{55}$.

En este mismo sentido, la creación del llamado "Sernac Financiero" por la Ley 20.555, modificatoria de la Ley 19.496, sobre protección de los derechos de los consumidores, que dota de atribuciones en materias financieras -entre otras- al Servicio Nacional del Consumidor, regula

\footnotetext{
51 Asunto C-333/94 P, Tetra Pack International SA/Comisión, Rec. 1996 p. I-5951. Disponible en: http://curia.europa.eu/juris/liste.jsf?language=es\&jur=C,T,F\&num=C-333-94\&td=ALL.

52 Villar (2005) 29.

53 Son aquellos mercados en los que se comercializan productos complementarios (productos secundarios), que se compran una vez que se ha adquirido otro producto (producto primario) con el que están relacionados.

54 Pace, Lorenzo Federico (2007), Derecho Europeo de la Competencia. Prohibiciones antritrust, control de las concentraciones y procedimiento de aplicación, Madrid: Marcial Pons, p.117.

55 VAldés Prieto (2006) 571.
} 
precisamente aquellas figuras de consumo en que se contratan varios productos o servicios simultáneamente, o que el producto o servicio principal conlleve la contratación de otros productos o servicios conexos, imponiéndole en tales casos a las empresas proveedoras la obligación de insertar un anexo en que se identifique cada uno de tales productos o servicios y se estipule claramente, además, en términos explícitos, cuáles son obligatorios por ley y cuáles voluntarios.

\section{1) EXClUSIONES QUE CONFIGURAN EL ABUSO DE POSICIÓN DOMINANTE}

En opinión de $\mathrm{CALvO}^{56}$, en este campo del derecho están en juego tanto la exclusión como el acceso a los mercados. La primera se produce cuando se aísla a quien no tiene acceso a la facilidad, mientras que en el segundo caso el propietario de la facilidad puede legítimamente negarse a permitir el acceso a ella.

Tratándose concretamente de la exclusión, esta puede asumir a su vez las siguientes formas o manifestaciones:

\subsection{1) Por vinculación}

La vinculación como modo de exclusión de los competidores se da cuando "el proveedor de un determinado producto supedita la adquisición del mismo (producto vinculante) a la adquisición de otro producto distinto (producto vinculado) que ofrece el propio proveedor o alguien relacionado con él, haciendo que el producto vinculante no pueda adquirirse separadamente" 57 .

Las ventas atadas son un típico ejemplo de este tipo de prácticas anticompetitivas, pues se caracterizan por supeditar la adquisición de un producto o servicio a la adquisición de otro. El riesgo que presentan a la competencia consiste en excluir un competidor presente en el mercado o restringir la entrada de nuevos competidores, impidiendo con ello la sustitución entre productos y perjudicando directamente a los consumidores.

Es en la sentencia Microsoft ${ }^{58}$ en donde se esbozan con precisión los supuestos de existencia de esta figura de exclusión, señalándose allí las siguientes:

a) Que el producto "que ata" y el producto "atado" sean diferentes.

b) Que la empresa sea dominante en el producto "que ata".

Calvo (2012) 230.

PACE (2007) 169.

Comp/C-3/37.792/2005. Disponible en:http://www.microsoft.com/enus/news/download/ legal/EuropeanCommission/ECSO 6 Annex\%204\%20-\%20Broy\%20Report $\% 20$ (NC\%20

Version).pdf. 
c) Que no exista la opción de adquirir el producto "atado" sin el "que ata".

d) Que la venta atada perjudique la libre competencia.

De lo expuesto se deduce que una empresa que ocupa una posición dominante en un mercado secundario a través de la vinculación o agrupación, puede excluir con mayor facilidad a los competidores del mercado vinculado. Puede tratarse perfectamente de un mercado secundario e indirectamente también de una exclusión horizontal del mercado del vinculante, en virtud de un acaparamiento de mercado. El abuso se manifiesta cuando la empresa detenta una posición de dominio en el mercado vinculante que, como resultado, le permite realizar prácticas excluyentes en el mercado secundario. Si tanto en el mercado vinculante como en el vinculado la empresa goza de una posición dominante, existe mayor riesgo de que se configure un abuso de posición dominante ${ }^{59}$.

\subsection{2) Por agrupación}

Es aquella modalidad de venta que se ofrece en forma de "paquete", comprendido por dos o más productos relacionados aunque sustituibles entre sí, haciendo imposible adquirir solo uno de los productos. Por otra parte, la agrupación mixta es aquella en que existe la posibilidad de comprar el paquete propiamente tal o los componentes por separado, siempre otorgando beneficios para quienes adquieran el paquete, beneficio reflejado en forma de descuentos.

\section{6) BARRERAS DE ENTRADA}

La doctrina económica ${ }^{60}$ define las barreras de entrada como los costos que soportan los competidores entrantes a un mercado, los que, sin embargo, no han soportado los operadores ya presentes en ese mercado

59 Pace (2007) 170. A su vez, el TDLC conoció de este tipo de abuso en mercados vinculados en el caso VTR (117/2011), en él la empresa Liberty Media Corp., perteneciente al mercado de la televisión por cable de EE.UU., dueńa a su vez de una de las empresas dominantes en el mercado de la televisión por cable chileno (VTR S.A.), fue autorizada a fusionarse (Resol. $\mathrm{N}^{\circ}$ 1/2004) con su competidor directo (Metropólis Intercom S.A.), infringiendo con ello la condición impuesta por el tribunal en orden a que el grupo Liberty no adquiriera otras empresas pertenecientes al mismo mercado en Chile, intentando evitar de esa forma vincular ambos mercados (el norteamericano y el chileno), así como también el riesgo de abuso de posición dominante en dichos mercados.

60 Stigler Renton, George (2002). (Premio Nobel de Economía 1982, miembro de la Escuela de Chicago). Citado por Pinkas Flint Blanck, Tratado de defensa de la libre competencia: estudio exegético del D.L.701, Lima, Perú: Fondo Editorial PUCP, p. 225. 
para producir el bien de que se trate. Estas barreras pueden originarse, a su vez, en factores de muy diversa naturaleza:

a) Legales, como por ejemplo los monopolios establecidos por ley o disposiciones normativas que limitan el número de operadores posibles en un determinado mercado, o exigen la obtención de una autorización administrativa para prestar un servicio.

b) Económicas, como ocurre en sectores con elevados costos hundidos, cuya penetración requiere una costosa inversión en infraestructuras o marketing con un retorno poco factible en un período corto de tiempo.

c) Naturales, como por ejemplo aquellos en los que la geografía supone un factor determinante para el éxito comercial (como en la generación de energía eólica).

d) Tecnológicas, como en aquellos sectores que exigen cuantiosas inversiones en el desarrollo de nuevos productos en los que el operador dominante es titular de un gran número de patentes $\mathrm{u}$ otros derechos de propiedad industrial.

e) Reputacionales, que influyen de manera decisiva en aquellos sectores en los que existe un alto grado de fidelidad de los consumidores a la marca del operador dominante ${ }^{61}$.

Asimismo, para que esta situación se produzca es necesario que tal entrada sea cierta o probable, que se pretenda implementar en el corto plazo y que el nuevo operador posea una identidad específica.

\section{7) EL ABUSO DE POSICIÓN DOMINANTE DERIVADO DEL CONTROL DE UNA FACILIDAD ESENCIAL}

Si la facilidad esencial es controlada solo por una empresa, y además es imposible su duplicidad, e imprescindible, por ende, su uso para poder ingresar a un determinado mercado, la negativa injustificada de aquella en orden a facilitar su uso al resto de sus competidores constituye un abuso de dicha posición de control, produciéndose el problema principal que intenta resolver la teoría que comentamos.

61 Rodríguez Encinas, Ana; Martínez Corral, Borja (2006), "El Abuso de Posición de Dominio: situación actual y evolución previsible”, Madrid: Revista Actualidad Jurídica, crónica de legislación y jurisprudencia de la competencia, publicación trimestral del Estudio de Abogados Uría Menéndez, No 16, abril-junio, p. 59. 


\section{1) CONCEPTO DE ABUSO}

Para entender la concepción de abuso de posición dominante es necesario referirse al concepto de culpa e intención dañosa, conceptos que se relacionan con el análisis de una noción objetiva de una conducta determinada más que con la idea de una falta. El actuar abusivo supone, para configurarse como tal, una noción objetiva que contemple los comportamientos de una empresa en posición dominante que, por su naturaleza, persiga influir sobre la estructura del mercado. Como consecuencia de ello, el nivel de competencia se debilita ya que el abuso de posición dominante obstaculiza el desenvolvimiento normal del mercado mediante el uso de recursos diferentes de los que gobiernan una competencia normal, con el consiguiente perjuicio del resto de los competidores presentes en él y de los intereses de los consumidores. En conclusión, el mantenimiento del grado de competencia existe aún en el mercado relevante, pero se ve debilitado por efecto de las prácticas abusivas del agente en cuestión ${ }^{62}$.

Asimismo, cabe considerar en este sentido el principio de libertad contractual presente en el derecho privado, que caracteriza a los actos libres tanto en la acción como en su omisión, siendo el límite de ellas las normas que regulan nuestras acciones, las que en contraposición con dicha libertad, imponen conductas o deberes determinados a objeto de evitar cualquier actuar abusivo. Así, en razón de lo anterior, desde el punto de vista del derecho civil la forma correcta de reparar cualquier perjuicio que se causare o que se pudiera producir, se determina mediante la fijación de reglas de conducta, pero no a través del establecimiento de deberes impositivos o prohibiciones que aseguren el bienestar de los demás ${ }^{63}$.

Parece claro que la intencionalidad de la conducta no es un elemento que determine la antijuricidad, pero sí es un elemento que debe tenerse en cuenta junto con otros para acreditar la comisión del ilícito y en particular para establecer presunciones de ilicitud que podrán ser desvirtuadas por el operador cuya conducta se investiga ${ }^{64}$.

Todo abuso supone la reducción o amenaza de afectar el beneficio del operador dominante en el corto plazo, con el objetivo de obtener rentas monopólicas en el largo plazo. Para que una conducta sea abusiva en el plano de las libertades económicas, debe producirse en un mercado específico, por parte de un operador que goce de una posición dominante, $\mathrm{y}$ afectar perjudicialmente a consumidores y/o competidores.

\footnotetext{
62 Calvo Caravaca, Alfonso; Carrascosa González, Javier (2002), Mercado único y libre competencia en la Unión Europea, Madrid: Colex, p.1074.

63 Barros, Enrique (2006), Tratado de la responsabilidad extracontractual, Santiago: Editorial Jurídica de Chile, p. 124.

64 Odrizola/Irissarry (2008) 147.
} 


\section{2) FACILIDADES ESENCIALES Y PRÁCTICAS EXCLUSORIAS}

En lo que se refiere a las facilidades esenciales, las prácticas exclusorias dicen relación con el control de un activo esencial para competir de manera eficiente en un determinado mercado, y con la negativa del controlador de permitir su uso a los competidores. La doctrina de las Facilidades esenciales sostiene que para excluir a los competidores es indispensable controlar ciertos bienes necesarios para acceder o mantenerse en un mercado, de forma que solo aquel o aquellos que lo posean puedan ofrecer un bien o servicio de manera eficiente ${ }^{65}$.

El acceso al mercado en dichas condiciones se ve afectado por la negativa de utilizar un bien esencial o por la fijación de precios excesivos para su uso. Esta práctica consiste en "... el tratamiento discriminatorio, en que se le aplican a terceros contratantes condiciones desiguales para prestaciones equivalentes, lo que da como resultado una desventaja competitiva" 66 . En esos términos, es posible plantear que "el elemento referencial para determinar la producción del mencionado efecto de exclusión es la dependencia del cliente respecto del producto o servicio del operador dominante" ${ }^{67}$, considerando además la baja o nula sustituibilidad de ellos.

\section{3) OBLIGACIONES POSITIVAS Y NEGATIVAS}

Para mantener el equilibrio competitivo dentro de los mercados es necesario prohibir ciertos actos o comportamientos, que sin ser ilícitos, persiguen afectar la libre competencia. Ello implica no solo que las empresas dominantes se abstengan de realizar determinados actos, sino que también contribuyan con sus competidores en lo que la doctrina ha denominado la teoría de las facilidades esenciales para mantener de esa forma el equilibrio a que nos referimos.

\section{4) Mercados Regulados Y eXISTENCIA DE FaCilidades ESENCIALES EN DICHOS MERCADOS}

En algunos casos el Estado entrega la concesión de ciertas áreas de la economía a particulares, como una manifestación del principio de su rol subsidiario, otorgando con ello un monopolio legal en el mercado en que estos actúan. Un ejemplo que ilustra a cabalidad esta situación es el mercado de las empresas sanitarias. Según la normativa chilena, estas operan en aéreas urbanas bajo un sistema de concesiones dentro de un territorio operacional, con tarifas y normas de calidad propias de un mercado re-

\footnotetext{
65 Coloma, Germán (2009), Defensa de la Competencia, 2a ed., Argentina, Buenos Aires - Madrid, p. 137.

66 Calvo/Carrascosa (2002) 1087.

67 Odrizola/Irissarry (2008) 176.
} 
gulado, lo que las constituye en monopolios legales. Por su parte, en los territorios urbanos fuera del área de concesión las empresas sanitarias solo pueden prestar sus servicios obteniendo la correspondiente ampliación de concesión, mientras que en los sectores rurales la prestación de servicios sanitarios es absolutamente facultativa y existe libertad tarifaria ${ }^{68}$.

Los mercados o industrias reguladas son aquellas en las cuales la reglamentación de los respectivos negocios y actividades económicas es efectuada por autoridades públicas sectoriales ${ }^{69}$. En un escenario como el descrito, son incompatibles las autorizaciones monopólicas a través de las cuales se concede la explotación unilateral de un determinado negocio con la obligación impuesta por la misma autoridad de permitir el uso de una facilidad esencial al resto de los competidores. En este sentido, hay que tener presente que la concesión de explotación unilateral de un determinado negocio se otorga con el propósito de asegurar el acceso de los consumidores a la energía eléctrica, las redes sanitarias, las redes de telefonía, etc., imponiéndose por parte de la autoridad cuantiosas multas en caso de suspenderse la prestación del servicio de que se trate, y si se otorga el uso exclusivo y excluyente de una determinada estructura o facilidad esencial es precisamente con el fin de garantizar el consumo de toda la población; además, no hay que olvidar que, aunque se otorguen autorizaciones de este tipo por parte del Estado y sus órganos, no se pierde de vista ni la eficiencia ni la influencia que pudiera tener en otros mercados (aguas abajo o aguas arriba) el otorgamiento exclusivo del uso de una facilidad esencial.

En este mismo sentido, se ha señalado que "Las líneas de transmisión eléctrica, los oleoductos, las frecuencias aéreas, los puertos, las frecuencias radioeléctricas y otros activos tienen como denominador común el que representan insumos esenciales para la generación de servicios o productos finales"70. SERrA ${ }^{71}$ agrega que una característica común a los sectores de infraestructura, pero no exclusiva de estos, es la coexistencia de segmentos donde la competencia es posible con otros que aún son monopolios naturales. Las firmas que participan en los segmentos competitivos normalmente requieren para llegar a sus clientes tener acceso a los segmentos monopólicos, los que se denominan facilidades esenciales o cuellos de botella.

Lo anterior es relevante y necesario tener presente y en consideración, pues no debemos olvidar que parte de la doctrina y jurisprudencia

68 Serra, Pablo (2001), "Las facilidades esenciales en la doctrina de los organismos de competencia chilenos", trabajo preparado para la Conferencia Competition Policy in Infrastructure Services, organizada por la División de Infraestructura y Mercados Financieros del Banco Interamericano de Desarrollo, p. 31. Disponible en http://www.congreso.gob.pe/historico/ cip/materiales/infraestructura/pub 104 esentialfacilitieschile.pdf.

69 VALDÉs (2006) 415.

70 Jiménez, Susana; Rojas, Patricio (2009), Informe de libre competencia Santiago, P. Rojas Economistas Asociados, Número 1, p. 3

71 SERRA (2001) 9. 
de EE.UU. estima que habiendo algún ente estatal regulador, la aplicación de las essential facilities estaría muy limitada o no sería aplicable ${ }^{72}$.

\section{IV) LA TEORÍA DE LAS FACILIDADES ESENCIALES EN LA JURISPRUDENCIA DEL TDLC}

El objetivo de la Ley Antimonopolios chilena -Decreto Ley 211- es proteger la eficiencia económica en un mercado relevante o conexo, que puede alterarse por la presencia de un agente que abuse de su posición dominante en un mercado determinado.

Nuestra legislación castiga las conductas, actos o convenciones y prácticas comerciales que ejecuten las empresas, que configuren un abuso de posición dominante y monopólico, y cuya finalidad sea impedir o tratar de impedir, restringir, o entorpecer la libre competencia en las actividades económicas mediante prácticas predatorias, o de competencia desleal, realizadas con el objeto de alcanzar, mantener o incrementar una posición dominante (art. 3, letra c) del DL 211.

En la jurisprudencia nacional no existe un criterio uniforme ni ha sido frecuente la aplicación, hasta la fecha, de la teoría de las Facilidades esenciales, considerada principalmente en problemas surgidos en mercados regulados y que dicen relación con servicios básicos como los sanitarios. En efecto, en el último tiempo solo conocemos dos fallos del TDLC en este sentido:

a) El primero es la sentencia recaída en la demanda interpuesta por Inmobiliaria y Constructora Independencia Ltda. contra Aguas Nuevo Sur Maule S.A. (ANSM) ${ }^{73}$. En este caso, la conducta reprochada fue el establecimiento de cobros discriminatorios y abusivos al prestar servicios sanitarios a través de sus redes a proyectos inmobiliarios en zonas rurales que están fuera del área concesionada. El TDLC acogió en este caso la demanda, condenando a Aguas Nuevo Sur Maule a pagar una multa de \$600 millones y obligándola a evaluar de modo distinto la tarificación que se imponga a sus clientes fuera del área de concesión.

b) El segundo caso se origina en el requerimiento de la FNE en contra de las empresas de Servicios Sanitarios (ESS) ESSAL

72 Al efecto, ver Verizón Communications Inc. V. Law offices of Curtis V. Trinko, LL8 (02682) 540 V.S. 398 (2004) 305 F. 3d 89, reversed and remanded. Disponible en www.ftc. gov/ogc/briefs/02-682.pdf.

73 Sentencia de 2 de julio de 2009, causa caratulada "Constructora e Inmobiliaria Independencia Ltda. Con Aguas Nuevo Sur Maule S.A.”, Rol N85-2009. 
S.A. ${ }^{74}$, ESSBIO S.A., Aguas Andinas S.A. y ANSM, que fueron acusadas de realizar conductas que configuraban abuso de posición dominante en el mercado de la prestación de servicios de agua potable y alcantarillados en las zonas aledańas o próximas a sus instalaciones y correspondientes aéreas de concesión. La Fiscalía Nacional Económica, junto con las respectivas multas, solicitó además la imposición de medidas correctivas y propuso modificaciones de normas legales y reglamentarias para facilitar la prestación de servicios sanitarios en términos competitivos y en condiciones de transparencia.

El TDLC acogió también el requerimiento de FNE, imponiendo multas de $\$ 566$ millones y $\$ 1.060$ millones, respectivamente, y obligando además a ANSM, ESBBIO, ESSAL y Aguas Andinas (todas sanitarias) a modificar los modelos de evaluación para prestar servicios fuera del área de concesión, por uno que sea público, transparente, objetivo y no discriminatorio.

En este mismo sentido, cabe destacar respecto de la sentencia antes mencionada contra ANSM, lo que dice relación con la calificación que dio el TDLC a las instalaciones de las ESS, señalando que era recomendable permitir el acceso a terceros de las mismas (instalaciones) a cambio del pago de una tarifa regulada. En particular, el Tribunal consideró que la existencia de las economías de escala y las características de facilidad esencial de algunas plantas de tratamiento dificultaba la competencia entre prestadores de Servicios Sanitarios por las concesiones de nuevas aéreas urbanas, entendiendo que la interconexión de posibles nuevos entrantes depende en la práctica de las concesionarias actuales. En este contexto, se recomendó un cambio en la ley a fin de que la interconexión sea obligatoria y tarificada por la Superintendencia de Servicios Sanitarios, tanto en aéreas rurales como para futuros concesionarios de aéreas urbanas ${ }^{75}$.

\section{CONCLUSIONES}

1) Si bien la teoría de las Facilidades esenciales surgió en EE.UU. el año 1912 con motivo del conocimiento del caso Terminal Railroad Association, y en Europa en relación al conocimiento del caso Bron$n e r^{76}$, ella ha tenido una evolución significativa en la doctrina y en la

\footnotetext{
74 Requerimiento de Fiscal Nacional Económico en contra de ESSAL y otras, Rol N¹072006, acumulada a la causa Rol Nº79-2005 TDLC.

JimÉNEZ/RoJAs (2009) 4 y ss.

76 Sentencia de la Corte Europea de Justicia del 26 de noviembre de 1998, "Oscar Bronner GmbH \& Co. KG contra Mediaprint Zeitungs y otros”, caso C-7/97, [1998] ECR I-7791. Ver
} 
jurisprudencia comparada y nacional, en especial en cuanto al objeto sobre el cual puede aplicarse. Utilizada en un principio solo respecto de instalaciones físicas (inmuebles, estructuras corpóreas, oleoductos, vías férreas, etc.), la señalada teoría ha experimentado una expansión en nuestros días hacia otro tipo de bienes, debido principalmente a la alta capacidad y desarrollo tecnológico que han alcanzado las empresas. De allí que actualmente la teoría de las Facilidades esenciales también ha considerado problemas en relación con bienes intangibles, como acceso a líneas de transmisión, carreteras de comunicación, patentes de invención y otros.

Incluso, en determinadas circunstancias, la negativa del titular de una propiedad intelectual a licenciar su derecho puede perjudicar el bienestar del consumidor, o más amplio aún, el bienestar social ${ }^{77}$.

2) La doctrina de las Facilidades esenciales fue creada como un sustento a la imposición de sanciones y otros remedios judiciales ante la negación de contratar por parte de un monopolista, bajo la Sección Segunda de la Sherman Act. A pesar de tener casi cien años de historia en el derecho comparado, la doctrina de las Facilidades esenciales ha sido un tópico un tanto ajeno al análisis y estudio en la doctrina nacional. Sin embargo, esto no ha sido obstáculo para que haya encontrado asidero en nuestro Tribunal de Defensa de la Libre Competencia, como se desprende del análisis que da cuenta el presente estudio. La teoría de las Facilidades esenciales se encuentra plenamente vigente en la actualidad, pues no se debe dejar de considerar que en épocas de inestabilidad y crisis económicas, como la que actualmente vivimos, conflictos como el abuso de posición dominante, los acuerdos colusorios, las prácticas concertadas, y especialmente el gran número

en http://eur-lex.europa.eu/LexUriServ/LexUriServ.do?uri=CELEX:61997J0007:ES:HT ML,

77 El profesor Hugo Gómez, respecto de bienestar social, señala que la regulación social corrige las externalidades originadas por el desarrollo de actividades económicas. Estas políticas, se materializan en la exigencia de licencias y autorizaciones; el registro de productos de consumo humano; la regulación de especificaciones técnicas; el cumplimiento de normas ambientales; la exigencia de un capital social mínimo y restricciones en determinados actos de gestión y en el manejo de inversiones. La regulación económica se centra en la corrección de los monopolios naturales (por lo general). Como en estos escenarios la competencia no es posible, la regulación fuerza "artificialmente" la competencia vía el acceso a facilidades esenciales, así como regula el precio y calidad de los servicios domiciliarios, simulando los resultados de un mercado competitivo, todo ello, con el fin de asegurar el máximo bienestar de los actores de una sociedad de mercado, competidores, consumidores, y en general, la sociedad toda (ver en Revista de la Competencia y la Propiedad Intelectual, Año 3, No 5, 2007, Instituto Nacional de Defensa de la Competencia y de la protección de la Propiedad Intelectual-INDECOPI). El "Norte" de las Políticas Públicas: Orientando a las Autoridades de Competencia protección al Consumidor y Regulación, Perú. Disponible en: http://aplicaciones.indecopi.gob.pe/ArchivosPortal/boletines/recompi/castellano/articulos/primavera2007/GOMEZ.pdf. 
de fusiones que se han realizado últimamente y que se seguirán produciendo en el futuro, lleva a concluir que los conflictos planteados en la teoría de las Facilidades esenciales ocurrirán más temprano que $\operatorname{tarde}^{78}$. Esta apreciación se reafirma aún más por el carácter restrictivo que tiene la teoría, ello a objeto del "refusal to deal" o negativa de venta, hecho que en la práctica mantiene en una sólida posición a esta doctrina, dejando sí establecido que su aplicación debe ser excepcional, para evitar incurrir en excesos que desincentiven las inversiones, al obligar a las empresas a compartir sus activos esenciales.

3) La jurisprudencia chilena ha aportado valiosos elementos teóricos y doctrinales, pero está muy lejos de sentar una doctrina propia, uniforme y generalmente aceptada y reconocida por todos los operadores del mercado. Creemos, por lo mismo, que ello debería ser un incentivo para seguir trabajando y analizando en detalle estas materias, toda vez que la aplicación de los múltiples acuerdos comerciales que ha suscrito nuestro país como el TLC con Estados Unidos, el acuerdo de libre comercio con la Unión Europea, el tratado de MERCOSUR y otros, con seguridad nos planteará situaciones de esta naturaleza, donde la teoría de las Facilidades esenciales tendrá un rol importante que jugar. El panorama descrito nos obligará por lo mismo a enfrentar con mayor conocimiento y preparación la resolución de estos conflictos, siendo de vital importancia el desempeño de nuestros organismos encargados de la defensa de la libre competencia como la Fiscalía Nacional Económica y el Tribunal de Defensa de la Libre Competencia, cuyo criterio inspirador necesariamente debería ser, a nuestro juicio, el proteger los mercados para que sean cada día más libres y competitivos y no, necesariamente, centrar su accionar en el resguardo de los competidores, los que saben proteger sus intereses .

\section{Bibliografía}

- Araya IbÁÑez, Álvaro, "Doctrina de las Facilidades Esenciales en los fallos del Tribunal de Defensa de la Libre Competencia”, Novoa \& Araya Abogados Limitada, Serie notas y artículos de interés Número 1, septiembre 2011, disponible en http://www.nyaabogados.cl/docs/ NotasyArticulosNA_N1_Facilidades\%20Esenciales.pdf.

78 Sobre la vigencia, revitalización y necesidad de armonizar la doctrina de las Facilidades esenciales, ver el trabajo de los profesores Spencer Weber Waller y William Tasch, Harmonizing Essential Facilities, de Loyola University Chicago, 76 Antitrust L.J.3 (2010); como también el trabajo de Spencer Weber Waller y Brett M. Frischmann, "Revitalizing Essential Facilities”, Loyola University Chicago, 75 Antitrust L.J.1 (2008). 
- Astesiano, Gastón, "La Doctrina de las facilidades esenciales en los Estados Unidos de Norteamérica y su recepción en el Derecho argentino. Una primera aproximación”. http://cdi.mecon.gov.ar/ biblio/docelec/mu1007.pdf.

- Barros Bourie, Enrique (2006), Tratado de la responsabilidad extracontractual, Santiago, Editorial Jurídica de Chile.

- Bello Martín-Crespo, María Pilar; Hernández Rodríguez, Francisco y otros (2009), Derecho de la Libre Competencia Comunitario y Español, Thomson Aranzadi, Madrid.

- Beneyto Pérez, José María y Maillo González-Orus, Jerónimo (2005), Tratado de derecho de la competencia, Unión Europea y España, Barcelona, Bosch.

- Bolívar Gacitúa, Natalia (2010), Las Concentraciones de Empresas, Regulación y Criterios de decisión de los órganos de la Unión Europea, Memoria de tesis para optar al grado de Máster en Derecho Privado Patrimonial de la Universidad de Salamanca, España.

- Cabanellas de las Cuevas, Guillermo (2010), Contratos de Licencia y Transferencia de Tecnología en el Derecho Económico, Editorial Heliasta, Buenos Aires.

- Calvo Caravaca, Alfonso y Carrascosa González, Javier (2002), Mercado único y libre competencia en la Unión Europea, Madrid, Colex.

- Calvo Caravaca, Alfonso y Rodríguez Rodrigo, Juliana (2012), La Doctrina de las Infraestructuras Esenciales en Derecho Antitrust Europeo, Revista de Derecho de la Competencia y la Distribución, Monografía N 6, Madrid, Wolters Kluver.

- Catrón Silo, Jimena (2001), "Cobro de tarifas por uso de red de cajeros enciende disputa en la industria bancaria", Diario Financiero, Santiago, miércoles 2 de noviembre de 2011.

- Coloma, Germán (2009), Defensa de la competencia, Buenos AiresMadrid, 2a ed., Ciudad Argentina.

- Department Of Justice United States, Federal Trade Commission, Bureau of Economics, Washington, D.C., United States.

- Gómez, Hugo (2007), "El "Norte” de las Políticas Públicas: Orientando a las Autoridades de Competencia protección al Consumidor y Regulación”, Revista de la Competencia y la Propiedad Intelectual, Año 3, $\mathrm{N}^{\circ}$ 5, Instituto Nacional de defensa de la Competencia y de la protección de la Propiedad IntelectualINDECOPI), Perú. Disponible en: http://aplicaciones.indecopi. gob.pe/ArchivosPortal/boletines/recompi/castellano/articulos/ primavera2007/GOMEZ.pdf.

- Humpe, Christophe; Ritter, Cyrl, Refusal to deal, Brussels, Global Competition Law Centre, Julio, 2005, p. 32 Disponible en www. http:/ssrn.com/abstract=771907>. 
- Jiménez Latorre, Fernando; Cañizares Pacheco, Enrique, "Dificultades para la definición del mercado relevante", informe preparado para el Segundo Seminario de Derecho y Economía de la Competencia, organizado por la Fundación Rafael del Pino, Madrid, $18 / 10 / 2005$.

- Jiménez, Susana y Concha, Paulina (2011), Facilidades esenciales y su análisis a la luz de la jurisprudencia chilena, Santiago, Instituto Libertad y Desarrollo, Serie Informe 211.

- Jiménez, Susana y Rojas, Patricio (2009), "Informe de libre competencia", Santiago, P. Rojas Economistas Asociados.

- Kaplow, Louis (2010), "Why (ever) define markets", USA, Harvard Law Review, p.437 a 517.

- Montt Rettig, Paulo y Nehme Zalaquett, Nicole (2009), "Conductas exclusorias y libre competencia: El caso de la negativa de venta en presencia de instalaciones esenciales", Anales de Derecho Universidad Católica 5.

- Morandé, Felipe y Doña, Juan Esteban (2011), Libre competencia y regulación: Estudio de casos, Santiago, Universitaria.

- Navarro, María del Carmen (2004), Las conductas conscientemente paralelas, Gaceta Jurídica de la Unión Europea y de la Competencia, № 232.

- Navarro Varona, Edurne y Baches, Sergio (2004), El nuevo sistema comunitario de control de concentraciones, Actualidad jurídica, crónica de legislación y jurisprudencia de competencia, publicación trimestral del Estudio de Abogados Uria Menéndez, Madrid No 8.

- Odrizola, Miguel e Irissarry, Belén (2008), Derecho español de la competencia, Barcelona, Bosch.

- Pace, Lorenzo Federico (2007), Derecho Europeo de la Competencia. Prohibiciones antritrust, control de las concentraciones y procedimiento de aplicación, Madrid, Marcial Pons.

- Pascual y Vicente, Julio (2001), "Abuso de posición dominante en mercados conexos: Doctrina reciente del Tribunal de Defensa de la Competencia”, Anuario de la competencia, Marcial Pons, Madrid.

- Pellisé, Jaume (2002), Mercado relevante, posición de dominio y otras cuestiones que plantean los articulos 82 TCE y 6 LEDC, Navarra, Aranzadi.

- Pellisé, Jaume (2002), "La Explotación Abusiva de una Posición Dominante (Arts. 82 TCE y LEDC), Madrid: Civitas Ediciones.

- Peña, Miguel, y Ramos, Ana (2001), "Doctrina de los recursos esenciales en la Unión Europea y España, caso Movilpago", Anuario de la competencia, Marcial Pons, Madrid.

- Pitofsky, Robert, The Essential Facilities Doctrine under United States, disponible en http://www.ftc.gov/os/comments/ intelpropertycomments/pitofskyrobert.pdf. 
- Rencoret Gutiérrez, Pedro (2010), La Doctrina de las facilidades esenciales ante el Tribunal de Defensa de la Libre Competencia (Memoria para adquirir el grado académico de Licenciado en Ciencias Jurídicas y Sociales), Universidad de Chile, Facultad de Derecho, Departamento de Derecho Económico, Santiago.

- Rodríguez Encinas, Ana; Martínez Corral, Borja, El Abuso de Posición de Dominio: situación actual y evolución previsible artículo publicado en la Revista de Empresa, publicación del Estudio de Abogados Uría Menéndez, No 16, Abril-Junio 2006, Madrid.

- Serra, Pablo (2001), "Las facilidades esenciales en la doctrina de los organismos de competencia chilenos", trabajo preparado para la Conferencia Competition Policy in Infrastructure Services, organizada por la División de Infraestructura y Mercados Financieros del Banco Interamericano de Desarrollo, disponible en http://www. congreso.gob.pe/historico/cip/materiales/infraestructura/pub_104_ esentialfacilitieschile.pdf.

- Smith, Adam, Investigación sobre la naturaleza y causa de las riquezas de las naciones, Décimo quinta reimpresión en español año 2006, Fondo de Cultura Económica, México, D.F.

- Tovar Mena, Teresa (2006), Derecho de la Competencia y Telecomunicaciones, Lima, ARA Editores.

- Tribunal de Defensa de la Libre Competencia, "Sentencias numeradas 1-12", www.tdlc.cl.

- Valdés Prieto, Domingo (2010), Libre competencia y monopolio, Santiago: Editorial Jurídica de Chile.

- Villar Rojas, Francisco José (2005), Las instalaciones esenciales para la competencia, Granada: Comares.

- VV.AA., Anuario de la Competencia 2001 (2002), Madrid, Marcial Pons.

- Waller, Spencer Weber y Tasch, William (2010), "Harmonizing Essential Facilities", Loyola University Chicago, 76 Antitrust L.J.3.

- Waller, Spencer Weber y Frischmann, Brett M. (2008), "Revitalizing Essential Facilities", Loyola University Chicago, 75 Antitrust L.J.1. 